\title{
EDUCAÇÃO NA FRONTEIRA DO BRASIL COM O PARAGUAI: DESAFIOS E PERSPECTIVAS POLÍTICAS
}

\author{
Mara Lucinéia Marques Correa Bueno * \\ Kellcia Rezende Souza**
}

\begin{abstract}
RESUMO: O presente artigo tem por objetivo identificar como a integração regional beneficiou a educação no contexto marginalizado de fronteira do Brasil com o Paraguai. E, buscou responder a pergunta: O processo de integração regional trouxe benefícios para a educação na fronteira do Brasil com o Paraguai? Para tanto, organizou-se três seções que visam atender ao objetivo e responder ao questionamento central da pesquisa, tecendo inicialmente considerações sobre globalização, a integração regional e a constituição de blocos econômicos. Em seguida situa-se o contexto brasileiro focando na criação do Mercosul, do Setor Educacional do Mercosul e a instituição de Planos de Ação que buscavam melhorar a qualidade da educação entre os países membros do bloco, visando a instauração de uma política educacional específica para a região de fronteira e a promoção da integração entre as nações. E, por fim apresenta-se os desafios para a efetivação da integração regional no contexto marginalizado da região fronteiriça, que perpassam questões relacionadas a vasta extensão territorial de fronteira do Brasil, até situações preconceituosas relacionadas a língua, aos povos e a própria segurança nas cidades fronteiriças, dentre outros desafios. Por fim, as considerações finais evidenciam que mesmo com a constituição do Mercosul, o processo de integração regional ainda não foi efetivado como uma política efetiva no atendimento as especificidades locais.
\end{abstract}

RESUMEN: Este artículo tiene como objetivo identificar cómo la integración regional ha beneficiado a la educación en el contexto marginado de la frontera de Brasil con Paraguay. Y buscó responder a la pregunta: ¿El proceso de integración regional trajo beneficios a la educación en la frontera brasileña con Paraguay? Para ello, se organizaron tres secciones con el fin de cumplir con el objetivo y responder al cuestionamiento central de la investigación, haciendo inicialmente consideraciones sobre globalización, integración regional y constitución de bloques económicos. A continuación está el contexto brasileño, enfocado en la creación de Mercosul, desde el Sector Educativo del Mercosur y la institución de Planes de Acción que buscaban mejorar la calidad de la educación entre los países miembros del bloque, apuntando al establecimiento de una política educativa específica para la frontera. región y la promoción de la integración entre naciones. $Y$, finalmente, están los desafios para la realización de la integración regional en el contexto marginado de la región fronteriza, que permean temas relacionados con la vasta extensión territorial de la frontera brasileña, a situaciones prejuiciadas relacionadas con el idioma, los pueblos y la seguridad en las ciudades fronterizas, entre otros desafios. Finalmente, las consideraciones finales muestran que incluso con la constitución del Mercosur, el proceso de integración regional aún no se ha implementado como una política eficaz para atender las especificidades locales.

PALAVRAS-CHAVE: integração regional; educação de fronteira; política educacional.

PALABRAS-CLAVE: integración regional; educación de frontera; política educativa.

DOI: $10.29327 / 214648.9 .33-4$ 


\section{INTRODUÇÃO}

O Brasil possui a maior extensão territorial da América do Sul com 8.510.820,623 km² (IBGE, 2018), apresentando uma faixa fronteiriça que compreende 23.086 quilômetros e faz fronteira com quase todos os países localizados no continente sul-americano: Venezuela, Guiana, Suriname, Guiana Francesa, Colômbia, Peru, Bolívia, Paraguai, Argentina e Uruguai, menos o Chile e o Equador (TORCHI E SILVA, 2016). A faixa de fronteira terrestre corresponde a 150 quilômetros de largura, abrangendo 588 municípios brasileiros, de um total de 5.570. Logo, percebe-se que o Brasil apresenta especificidades que o caracterizam como um país de vasta extensão territorial e fronteiriça. Dessa forma, a integração regional representa um elemento importante para justificar a circulação de pessoas, bens e serviços, além de construir um espaço regional integrado no subcontinente, como salienta Vizentini (2007). Mas não o isenta de se tornar um cenário marginalizado por apresentar especificidades distintas das demais regiões do país.

A pesquisa apresentada trata-se de um recorte da tese de doutoramento concluída e traz como objetivo: identificar como a integração regional beneficiou a educação no contexto marginalizado de fronteira do Brasil com o Paraguai. E, para isso busca responder o seguinte questionamento: $O$ processo de integração regional trouxe benefícios para a educação na fronteira do Brasil com o Paraguai? Para tanto, em aspectos metodológicos esse artigo trata da avaliação de uma política pública educacional e seus possíveis impactos, que para Palumbo (1989, p. 50) representa o quarto estágio em um ciclo de políticas, onde são avaliados o "impacto da política e os processos pelas quais ela está sendo implementada". As escolhas teóricas e normativas dessa pesquisa fundamentam-se na pesquisa bibliográfica e documental com base em Cellard (2008, p. 299), o qual salienta que é "[...] essencial saber compor com algumas fontes documentais, mesmo as mais pobres, pois elas são geralmente as únicas que podem nos esclarecer, um pouco que seja, sobre uma situação determinada". Destarte, essa análise se faz necessária pela escassez de material sobre o assunto na literatura acadêmica.

O trabalho foi organizado em três seções, além da introdução e considerações finais. Na primeira seção realizou-se um levantamento teórico sobre o surgimento da globalização que culminou no processo de integração regional entre os países formando assim blocos econômicos ao redor do mundo, os quais visavam o fortalecimento econômico entre as nações membro. Contudo ainda nessa seção direciona-se as discussões para a constituição do Mercosul com o objetivo de apresentar o contexto em que o Brasil está inserido. Já na segunda seção apresentou-se a composição do Setor Educacional (SEM) como uma tentativa de promover a integração regional também por meio da educação, esse Setor foi responsável por instituir Planos de Ação entre os países do bloco. E, na terceira seção discutiu-se sobre os principais desafios presentes para a efetivação de uma política educacional de fronteira que atenda as especificidades marginalizadas locais.

\section{GLOBALIZAÇÃO, INTEGRAÇÃO REGIONAL E MERCOSUL}


Após a Segunda Guerra Mundial as mudanças ocorridas foram imprescindíveis para compreender o movimento estabelecido entre os países na busca por prospecção em suas economias e na política em âmbito internacional. Para tanto, a globalização representou uma engrenagem impulsionadora para a abertura do comércio e das fronteiras, que dividiam as nações, visando o fortalecimento econômico por meio da formação dos blocos econômicos.

Com a finalidade de compreender esse movimento global, cabe contextualizar que o final do século XX trouxe transformações importantes ao sistema internacional, pois foi marcado de um lado pela urgência da atividade multinacional e de outro pela rápida expansão do comércio internacional (HIRST; THOMPSON, 1998). A década de 1980 corresponde ao fim da Guerra Fria ${ }^{1}$ e à dissolução do regime soviético, que foi alavancado pelos atritos entre os Estados Unidos e a então União Soviética, surgindo, assim, novas perspectivas a ordem mundial, ou seja, a ascensão do capitalismo (MARIANO, 2007). Para Sato (2000), o fim da Guerra Fria representou um período de mudança condicionante da política internacional, que resultou no desenvolvimento econômico, tecnológico e até mesmo no quadro de valores sociais como referenciais para a política exterior entre os países, sendo uma justificativa para uma ação política. Nesse contexto, surge a globalização que Held e McGrew (2001) conceituam como um processo cujos fluxos de comércio, capital e pessoas no globo, representam intensos e crescentes fluxos globais que entrelaçam os estados e a sociedade em sistemas mundiais e redes de interação. Sendo assim, a globalização circunda as nações, diminuindo as distâncias e aumentando de maneira expressiva as interações sociais, ou seja, por exemplo, quando uma crise se instaura em um país ela tem um impacto mundial. Logo, para fechar essa conceituação do autor, torna-se relevante evidenciar que "a globalização denota a escala crescente, a magnitude progressiva, a aceleração e o aprofundamento do impacto dos fluxos e padrões inter-regionais de interação social” (HELD; MCGREW, 2001, p. 13).

Já Chesnais (1995) estabelece que globalização vai além da abertura de fronteiras com a promoção do intercâmbio de bens e serviços, isto é, as trocas comerciais entre os países, pois oferece na realidade a "mundialização das operações do capital, em suas formas tanto industrial quanto financeira" (CHESNAIS, 1995, p. 04). E, esse cenário foi representado pelas empresas transnacionais que, ainda em ritmo lento, trouxeram essa oportunidade de aproximação tanto industrial quanto financeira entre as nações. Dessa forma, a globalização ainda estabelece o apoio mútuo entre as nações buscando instaurar uma nova ordem internacional, em que a economia e os Estados nacionais sejam fortalecidos, conforme Jessop (1998) enfatiza:

\footnotetext{
${ }^{1}$ Período que teve seu início após a Segunda Guerra Mundial (1945) e a extinção da União Soviética (1991), marcado por disputas estratégicas e conflitos, principalmente, entre os Estados Unidos e a União Soviética, objetivando a hegemonia política, econômica e militar no mundo, além de intensificar e estender o desenvolvimento do capitalismo.
}

DOI: $10.29327 / 214648.9 .33-4$ 
[...] o atual período de globalização envolve a proliferação de escalas espaciais (seja a terrestre, a territorial ou a telemática), a sua relativa dissociação em hierarquias complexamente entrelaçadas (mais que a simples acomodação de escalas) e um crescente enredamento das estratégias de escala, na medida em que as forças econômicas e políticas buscam as condições mais favoráveis à inserção na cambiante ordem internacional (JESSOP, 1998, p. 37).

Nessa direção, a globalização representou um momento de reforma e de transformações entre as nações, tanto em aspectos econômicos, sociais e políticos, quanto culturais, aspirando construir um sistema internacional, por meio da criação de instituições supranacionais e/ou transnacionais, que atendam às necessidades mundiais. Dale (2004) enfatiza que a globalização representa o dilaceramento de fronteiras entre países com a intenção de aproximar os povos e almejar interesses comuns, seja na área econômica, política ou social. Já Souza (2016) destaca que o processo de globalização se organiza pelo uso da tecnologia (virtualmente) e se sustentou em si mesmo, não na organização de um país.

Nessa perspectiva, a modernidade simbolizou um novo conceito de vida proveniente da Europa a partir do século XVII e que teve repercussão mundial (GIDDENS, 1991). A globalização sela este período de mudanças trazendo novos anseios e rumos às nações. Cabe evidenciar que o foco nessa pesquisa está centrado a partir da década de 1980, quando há mudanças significativas entre os países de fronteira visando a integração regional e o fortalecimento econômico. E, autores como Mariano (2007), Dale (2004), Ianni (1999), Hirst e Thompson (1998) concordam que o processo de globalização representou um avanço para as economias dos países, pois oportunizou a união de nações em busca de interesses comuns. Contudo, anterior ao sistema integrador houve o estabelecimento dos blocos econômicos que, segundo Queiroz (2007), propunha a abertura das fronteiras trazendo a ampliação das relações comerciais, dos intercâmbios e do trânsito de pessoas para negócios, investimentos, comércio, bem como o próprio turismo. Sendo assim, a formação dos blocos transcende as fronteiras econômicas e ganham novas dimensões que são também reflexos da globalização.

De acordo com Simões e Moroni (2002), a expansão do capitalismo e a criação de corporações transnacionais apontam para o desenvolvimento de uma nova ordem mundial, trazendo um incremento à guerra comercial entre os países e as empresas. Nesse cenário, surgem os blocos econômicos regionais. O interesse com a formação dos blocos é justamente criar regiões onde grupos de países, com interesses semelhantes, estivessem protegidos e pudessem comercializar produtos entre si, dificultando a entrada de mercadorias de países que não fizessem parte do bloco, bem como a livre concorrência com empresas de outros blocos. Alvares (2015) explicita que a formação dos blocos econômicos visa, também, o fortalecimento dos países diante das mudanças no mundo agora globalizado e justificam as adequações estruturais em cada nação para atender um modelo único supranacional. 
Conforme destaca Mariano et al. (2015), a integração regional se relaciona inicialmente aos discursos governamentais que ressaltam a relevância do conceito de pertencimento à região para a construção de um futuro comum, bem como a superação de desafios em cada país envolvido nesse processo. Os autores, então, avaliam que integrar países que apresentem interesses afins simboliza superar possíveis desavenças, bem como valorizar seus bens e serviços para, assim, "utilizar esses instrumentos regionais como importantes mecanismos de inserção internacional e de adequação ao sistema internacional, marcado pela globalização" (MARIANO et al., 2015, p. 36), garantindo a competitividade internacional. Para tanto, blocos começaram a se formar e encontros foram marcados para discutir a integração entre países.

Já Sato (2000) explicita que a integração regional é resultante da organização dos blocos econômicos e nesse cenário representa uma oportunidade às nações para inserção, como também condições competitivas no mercado globalizado e, dessa forma, busca-se poder de barganha e maior investimento externo. Em caráter político, a integração regional proporciona maior aproximação comercial com a comunidade internacional, além de oportunizar a participação em decisões de interesse comum com outros países. Queiroz (2007) acrescenta que além da quebra das barreiras tarifárias e do acesso facilitado a bens e a serviços, a integração regional proporciona direitos e garantias aos cidadãos pertencentes aos países do bloco.

Vigevani et al. (2008) trazem uma percepção de integração que contempla o "conceito de regionalismo aberto na perspectiva da plena inserção internacional" (VIGEVANI et al., 2008, p. 08), ou seja, tratam-se de vantagens de livre comércio entre países de interesse comum, mas sem criar políticas regionais para instrumentalizar a sustentabilidade da integração. Nesse ideário de fortalecimento econômico das grandes economias mundiais que apresentam os melhores Produto Nacional Bruto (PNB), há a organização de seis grandes blocos para selar o compromisso econômicos entre eles, que são: Associação Europeia de Comércio Livre (EFTA) ${ }^{2}$, o Pacto Andino (Comunidade Andina de Nações) ${ }^{3}$, a Comunidade para o Desenvolvimento da África Austral (SADC) ${ }^{4}$, o Acordo de Livre Comércio da América do Norte (NAFTA) ${ }^{5}$, O Acordo Estados Unidos-MéxicoCanadá (USMCA) ${ }^{6}$, a Cooperação Econômica da Ásia e do Pacífico (APEC) ${ }^{7}$. A Área de Livre Comércio das Américas (ALCA) ${ }^{8}$ e o Mercosul $^{9}$. Este último, representa o objeto de estudo pois foi firmado em 1991 reunindo Argentina, Brasil, Paraguai e Uruguai que assumiram o compromisso da mais abrangente iniciativa de integração regional na

\footnotetext{
${ }^{2}$ Fonte: https://www.efta.int/.

${ }^{3}$ Fonte: http://www2.camara.leg.br.

${ }^{4}$ Fonte: https://www.sadc.int/.

${ }^{5}$ Fonte: https://www.nafta-sec-alena.org/.

${ }^{6}$ Fonte: https://ustr.gov/.

${ }^{7}$ Fonte: http://www2.camara.leg.br/.

${ }^{8}$ Fonte: http://www.ftaa-alca.org/.

${ }^{9}$ Fonte: http://www.mercosul.gov.br/.
}

DOI: $10.29327 / 214648.9 .33-4$ 
América Latina. Foi marcada pelo contexto de redemocratização e reaproximação desses países ao final da década de 1980. Para Vizentini (2007, p. 82):

[...] o Mercosul representou o primeiro processo de integração sul-americano, e, também, latino-americano, a obter resultados concretos e a abrir alternativas regionais para uma melhor inserção internacional dos países do cone sul, nos quadros de uma ordem mundial emergente.

Nesse quesito Draibe (2007) concorda com Vizentini (2007) e acrescenta que o grande passo no processo de integração regional foi dado quando os países do bloco selaram o compromisso de integrar valores do Estado de Direito, da democracia e dos direitos humanos, de forma mais ampla no modelo estabelecido de desenvolvimento econômico regional estabelecido, a partir daquele momento pautado pela justiça e pela equidade. Já Neto (2014) enfatiza que o Mercosul ao implementar a fase de união aduaneira, melhorou a capacidade do Brasil em gerir seus objetivos internacionais, pois obteve vantagens como em negociações com os Estados Unidos e a União Europeia. E, além das questões econômicas, houve também uma aproximação no setor educacional, que será apresentado na próxima seção ao tratar sobre a organização do Setor Educacional do Mercosul (SEM) e a instituição de Planos de Ação pelos países membros no Mercosul.

\section{A COMPOSIÇÃO DO SEM E SEUS REFLEXOS NA EDUCAÇÃO}

O Tratado do Mercosul propunha o livre trânsito de bens e de serviços, além de uma política comercial única e tarifas comuns, bem como a coordenação política macroeconômica e de setor desde as áreas agrícolas até as de comunicações entre as nações parte. Enfim, trata-se de um acordo que priorizou a integração econômica entre os países do bloco. Logo, percebe-se que o setor educacional não fazia parte dos acordos entre as nações. Contudo, de acordo com Andrés (2010), desde o início das negociações para a criação do bloco a educação era pauta de discussão, já que era considerada "como instrumento central para a superação das disparidades regionais, a consolidação da democracia, o desenvolvimento econômico e social e a integração regional" (ANDRÉS, 2010 , p. 7). Sendo assim, além de se garantir a integração regional, econômica e social dos países do Cone Sul também se almejava o desenvolvimento educacional de cada região.

Logo, as negociações entre os responsáveis pela educação de cada nação tiveram início ainda na década de 1990. Tanto que em dezembro de 1991, o Conselho do Mercosul criou o órgão chamado Reunião dos Ministros de Educação (RME) dos países integrantes do grupo. Esse órgão foi o responsável por todas as decisões do setor educacional do bloco, tendo por missão definir planos e programas que orientem a definição de políticas e estratégias comuns para o desenvolvimento educativo regional. A partir daí acordos educacionais foram firmados (ANDRÉS, 2010). Para Cristofoli (2010), a Comissão de Ministros do Setor se tornou órgão máximo e tinha como principal missão propor medidas

DOI: $10.29327 / 214648.9 .33-4$ 
que fossem necessárias para a coordenação das políticas educacionais entre as nações parte. Nesse quesito, Alvares $(2015$, p. 77$)$ enfatiza que "desde a constituição do Setor Educacional do Mercosul, na medida em que se implementam planos, ações e metas, tem havido uma convergência para a implementação de políticas de regionalização". Sendo assim, a instauração do SEM no âmbito do RME trouxe um direcionamento para o Mercosul e a possibilidade de promover a integração regional por meio da educação, anseio já expresso pela organização anteriormente.

Contudo, Real (2013) aponta que a morosidade na implantação das medidas no SEM ocasionou implicações para as políticas educacionais, evidenciando o descompasso entre a composição organizacional, o planejamento e a execução das ações entre as nações parte. A estrutura organizacional do SEM tinha por objetivo "coordenar as políticas educacionais para a região" (BRASIL, 2015, p. 13), para o qual a integração do trabalho a ser desenvolvido era imprescindível. Santos e Junior (2017) salientam que o processo de integração regional teve cunho econômico, mas foi por meio da educação que aconteceu a propagação da cultura, pois houve a instauração do "[...] conhecimento recíproco das identidades e das diferenças tão necessário para uma integração mais autêntica e legítima, em todas as suas dimensões, e voltada para a pluralidade da região" (CUNHA, 1995, p. 10).

Nessa perspectiva, percebem-se duas possibilidades no contexto da integração regional. A primeira está relacionada ao processo de integração, tendo a educação como alicerce no âmbito do SEM. A segunda vê no processo integrador a possibilidade de desenvolvimento da educação como uma mercadoria. Contudo, detém-se aos documentos oficiais relacionados a primeira possibilidade que tem relação com a educação básica e não com o ensino superior. Sendo assim, o SEM apresenta-se como um órgão viabilizador de ações integradoras no âmbito mercosulino. Para firmar o compromisso e dar uma direção aos trabalhos do SEM, organizaram-se reuniões, as quais eram promovidas pelos ministros de educação pertencentes ao bloco do Mercosul que tinham por objetivo a discussão de pautas que promovam a integração entre as nações parte e resultem em ações governamentais que desenvolvam as políticas educacionais. Para Silveira (2016, p. 915), "os ministros de educação alinhavaram as condições operativas para obter a comparabilidade e convergência dos sistemas nacionais" com as reuniões do RME.

O ciclo de reuniões anuais do SEM teve início em 1992, na ocasião houve a aprovação do primeiro Plano para a educação em países integrantes do Mercosul o qual foi intitulado "Plano Trienal" e proposto pelo Comitê Coordenador Regional. Cabe salientar que esse Plano definiu as áreas estratégicas identificadas para a cooperação e o desenvolvimento de programas, linhas de ação e as atividades que orientam os esforços para expansão da educação (MERCOSUL, 1992). Para Santos e Junior (2017, p. 30), “o SEM passou a editar Planos de Educação do Mercosul (PEM), os quais apontavam os objetivos e as ações a serem engendradas para um determinado período" e, desta forma, passaram a ditar as normas e regras da integração educacional da educação básica ao ensino superior entre as nações parte.

DOI: $10.29327 / 214648.9 .33-4$ 
A cada ano ocorriam de uma a três reuniões do Setor para discutir ações que visavam a promoção da integração regional entre os países pertencentes ao bloco e vislumbravam a associação de novas nações. O segundo plano foi aprovado em 1998, intitulado de Plano Trienal do Setor Educacional do MERCOSUL (1998-2000) e o estabelecimento de novas metas para o novo período. E tiveram a associação de dois países ao bloco, Bolívia e Chile. Cabe mencionar que em todas as atas da primeira década do SEM houve o registro que perpetua o reconhecimento pelo apoio prestado e a participação dos organismos internacionais como a Organização das Nações Unidas para Educação, Ciência e Cultura (UNESCO), a Oficina Regional de Educação para a América Latina e o Caribe (OREALC), a Organização dos Estados Americanos (OEA) e a Organização dos Estados Ibero-americanos (OEI) ${ }^{10}$ nas ações do bloco. Ou seja, a presença dessas organizações evidencia que há um acompanhamento e interesse pelos desdobramentos das ações advindas por meio das reuniões do RME. Para Ianni (1999), a presença das corporações transnacionais representa uma facilitação na resolução de problemas, porém sem a preocupação, por parte dessas organizações, com as implicações e os custos sociais dessas manobras.

Em 2001, registrou-se a aprovação do Plano de Trabalho ou Ação 2001-2005 do SEM, o qual prometia promover uma maior integração regional. Já em 2006 foi aprovado o "Plano Operativo", com a definição de metas e de ações a serem incorporadas ao Plano do SEM (2006-2010), com a incorporação da Venezuela ao SEM e a representação dos países associados ao bloco - Bolívia, Equador e Colômbia, reforçando, portanto, o compromisso com a educação e o processo de integração regional. Naquele período, a incorporação da Venezuela e da Colômbia ao Mercosul demonstrava a relevância do bloco e o interesse dos países em fazer parte de um grupo forte que busca integrar ações, bem as nações fundadoras veem com bons olhos o interesse das nações vizinhas. Sobre essa situação, Menegatti (2016) esboça o fortalecimento do Mercosul como um bloco que, apesar das dificuldades, ambiciona a consolidação da integração regional.

No decorrer dos encontros dos ministros de educação no RME percebeu-se a necessidade de uma maior integração educacional entre os países e, no ano de 2010 o ministro brasileiro propôs criação de um programa de intercâmbio entre estudantes de educação básica para o aprofundamento das línguas portuguesa e espanhola. Este programa tinha por objetivo ampliar os conhecimentos linguísticos e difundir as duas línguas entre os países do Mercosul. Recomendou-se, então, que no próximo plano do SEM haja uma maior preocupação com a qualidade da educação levando em consideração a justiça social, os critérios e indicadores educacionais, que evidenciem o espaço regional ocupado pelo Mercosul, realizando também a construção da identidade, da memória, da

\footnotetext{
${ }^{10}$ A OEI é uma organização internacional para a cooperação no campo da educação, ciência e cultura no contexto do desenvolvimento integral, da democracia e da integração regional. Dentre os países membros estão: Argentina, Bolívia, Brasil, Colômbia, Costa Rica, Cuba, Chile, República Dominicana, Equador, El Salvador, Espanha, Guatemala, Guiné Equatorial, Honduras, México, Nicarágua, Panamá, Paraguai, Peru, Portugal, Uruguai e Venezuela.
}

DOI: $10.29327 / 214648.9 .33-4$ 
interculturalidade e da multiculturalidade, bem como a integração social e cultural dos povos.

Em 2011, foi aprovado o Plano de Ação do SEM (2011-2015) e, novamente, nas discussões sobre a qualidade da formação docente no contex to do SEM, comprometendose a ampliar os espaços de participação, bem como a busca de uma melhor qualificação para os profissionais da educação. Diante dessas discussões, o governo brasileiro editou a Portaria n. ${ }^{\circ}$ 798/2012, instituindo o Programa Escolas Interculturais de Fronteira $(\mathrm{PEIF})^{11}$ para dar continuidade às ações do Programa Escolas Bilíngues de Fronteira $(\mathrm{PEBF})^{12}$ na promoção da integração regional por meio da educação intercultural e bilíngue. E, no ano de 2015, durante as reuniões houve início das discussões sobre o Plano de Ação do SEM (2016-2020). Borges (2014) enfatiza que o PEIF veio para fortalecer as políticas educacionais relacionadas à fronteira. O PEBF e o PEIF se revelaram como um marco para as escolas fronteiriças, trazendo à reflexão a questão da interculturalidade e do bilinguismo, que estão presentes no contexto marginalizado de fronteira, mas são desconhecidas pelo restante do país. E, tornaram-se a primeira iniciativa, via política educacional, específica para a região de fronteira.

Vale ressaltar que os conteúdos das reuniões realizadas nos anos seguintes ainda não foram divulgados no portal do Mercosul, porém, levando em conta os dados de ações do Setor nessa última década é possível dizer que houve avanços na melhoria da qualidade da educação e em de ações envolvendo a primeira infância. Por esse motivo cabe salientar que a criação do SEM e do RME, conforme Souza (2017), representou um salto para o processo de integração já que as discussões e as ações em prol da educação necessitavam de um setor específico. E, para dar sentido as discussões sobre o processo de integração regional, especialmente entre Brasil e Paraguai, na próxima seção apresentar-se-á os principais desafios presentes na educação em região de fronteira.

\section{BRASIL E PARAGUAI: OS DESAFIOS DA EDUCAÇÃO EM UM CONTEXTO DE FRONTEIRA}

Quando se fala de fronteira, logo se imagina pessoas diferentes, com língua e culturas distintas. E, ao relacionar essa realidade com a educação, logo mensura-se os desafios

\footnotetext{
${ }^{11}$ Programa educacional firmado em 2012 entre os países do Mercosul visando a formação continuada de professores em exercício, o intercâmbio entre docentes e o ensino nas línguas pertencentes aos países membros no Mercosul. No Brasil, houve a parceria das secretarias de educação estaduais e municipais com as universidades públicas para a realização da formação continuada para os professores fronteiriços.

${ }_{12}$ Programa educacional firmado em 2008 entre o Ministério da Educação no Brasil e Ministerio de Educación, Ciencia y Tecnología na Argentina para a promoção de formação continuada, o intercâmbio entre professores (chamado de cruce) e o ensino nas línguas pertencentes aos países membros no Mercosul. A realização da formação continuada ficou a cargo do Instituto de Investigação e Política Linguística (IPOL). Trata-se uma instituição sem fins lucrativos, de caráter cultural e educacional, fundada em 1999, com sede em Florianópolis, Santa Catarina, Brasil
}

DOI: $10.29327 / 214648.9 .33-4$ 
presentes em um contexto fronteiriço. Mas, o conceito de fronteira ainda traz inquietudes e divergências. Para tanto, recorre-se a Fernandes e Hellmann (2016) para definir fronteira como um limite, uma marcação de poder territorial ou ainda uma marcação de domínio de área. Já, para Albuquerque (2010, p. 589), "as fronteiras [...] são fluxos, mas também obstáculos, misturas e separações, integrações e conflitos, domínios e subordinações". Elas representam espaços de poder, de conflitos variados e de distintas formas de integração cultural. E, Rodrigues (2014) conceitua fronteira como um espaço com características geográficas peculiares e que materializa uma relação pacífica entre os dois países.

Com a finalidade de compreender a realidade a qual se insere a pesquisa, o Brasil e o Paraguai, a seguir, serão destacadas algumas especificações dos dois países analisados. A começar pelo Brasil, que possui cerca de $23.086 \mathrm{~km}$ de fronteira, onde $15.719 \mathrm{~km}$ são de limite com países do continente sul americano, com exceção do Chile e do Equador, bem como uma população de cerca de 207,8 milhões de habitantes. A luz da realidade brasileira no setor educacional, percebe-se que a influência internacional na concepção das políticas para a educação foi significativa. No cenário econômico, o Brasil possui uma renda média per capita de U\$323,46, um Produto Interno Bruto (PIB) em torno de U\$ 1,6 trilhão (BANCO MUNDIAL, 2016) e uma população estimada em 209.146.437 habitantes, segundo dados divulgados pelo Instituto Brasileiro de Geografia e Estatística (IBGE), em 2017. Agora, com relação às especificidades do país vizinho, de acordo com o Ministério das Relações Exteriores do Brasil, o Paraguai possui uma extensão territorial de $406.750 \mathrm{~km}^{2}$, sendo que $3.484 \mathrm{~km}$ são de fronteira com a Argentina, a Bolívia e o Brasil. Conta com uma população estimada em 6.725 milhões, distribuídos em 17 departamentos (estados), conforme dados do Banco Mundial (2016). De acordo ainda com a mesma fonte, o país apresenta uma população estimada em cerca de 6.342 milhões de habitantes em 2009, tendo um PIB, em 2016, de U\$27,44 bilhões e uma renda per capita de US\$ 9.400 (BANCO MUNDIAL, 2016).

Diante dessa realidade distinta, cabe salientar que são muitos os desafios presentes na fronteira do Brasil com o Paraguai. Além dos desafios econômicos e de dimensões territoriais das duas nações, pode-se destacar os Planos de Ação do SEM que caminharam timidamente para o processo de integração regional por meio da educação e, como já evidenciado por Real (2009), as ações no âmbito do Mercosul são morosas e no SEM seguem a mesma perspectiva. Contudo, a qualidade da educação representa um ponto que perpassa por todos os Planos, mas ainda representa um desafio aos países do bloco. Nessa perspectiva, Gatti (2013) destaca que o aperfeiçoamento representa um desafio para as políticas educacionais e, atualmente, há uma preocupação maior entre os países de buscar na educação a superação de suas limitações de codificação e interpretação de uma informação, o que permite ao indivíduo a criação. No Brasil, ainda conforme Gatti (2014), essa necessidade relatada não se concretizou com a mesma velocidade do que em outras nações, já que não houve a formulação de políticas educacionais nacionais que contemplassem essa mudança nos currículos. E, focando na realidade entre Brasil e Paraguai os desafios perpassam sobre a interculturalidade no qual Flores (2012) enfatiza

DOI: $10.29327 / 214648.9 .33-4$ 
que esse trabalho possibilita a construção da democracia em um ambiente multicultural, explicitando que há desafios para o desenvolvimento de uma educação intercultural:

Uma cultura pedagógica inovadora, um processo educativo transformador não somente da mentalidade dos educandos, mas da organização social como um todo. A participação de diferentes setores da comunidade no processo educativo é fundamental para que a escola alcance os fins e objetivos que esta mesma sociedade lhe conferiu (FLORES, 2012, p. 56).

Outro aspecto desafiador recai sobre preconceito entre brasileiros e paraguaios, situação comum na fronteira. Assim como, para Haygert e Sturza (2015), a visão preconceituosa da fronteira, tanto de quem reside quanto das pessoas que vêm de fora, por conta da cultura e da língua diferentes, representam situações comuns na vida escolar das crianças, as quais sofrem violência psicológica e, ainda assim, em meio à dificuldade, conseguem transpor as barreiras e superar os desafios. Essa realidade se aplica principalmente às crianças paraguaias que estudam no Brasil. Desse modo, Pereira (2014) enfatiza que o preconceito está implícito no cotidiano das pessoas e que os paraguaios só buscam uma vida melhor para suas crianças:

Tanto as crianças quanto seus pais desejam a escola brasileira, mas, estando nela, sentem necessidade de ajustar e alinhar sua identidade na relação com os colegas e professores brasileiros. A escola brasileira é pública, e por esta razão, os pais não desembolsam para manter seus filhos estudando; os alunos recebem kit escolar, o que se coloca como mais um atrativo para que as famílias optem por manter seus filhos nesta escola (PEREIRA, 2014. p. 21).

Nessa perspectiva, Sturza (2014, p. 23) enfatiza que a questão linguística permeia a realidade fronteiriça e que a diversidade causa crise identitária e as "atitudes linguísticas, os preconceitos, as diferenças e as similitudes culturais se mostram mais claramente quando se adentra no universo, não só escolar como das comunidades onde estão inseridas as escolas". Outro aspecto desafiador recai sobre a segurança na fronteira, pois há receio por parte das pessoas que não vivenciam a fronteira diariamente, do risco eminente de violência; muitas vezes trata-se de preconceito. Como salienta Sturza (2006), na fronteira podem ocorrer situações lícitas e ilícitas, mas, para Pereira (2014), existem interpretações malvistas e deturpadas sobre a região fronteiriça.

Logo, a fronteira precisa ser um espaço de trocas interculturais, e não visto como um local perigoso. O processo de integração regional, nesse contexto, pretende minimizar essas diferenças e preconceitos presentes na região. E, dessa forma evidencia-se os desafios presentes no contexto de fronteira buscando, apesar das dificuldades, promover a integração entre os povos também por meio da educação.

\section{CONSIDERAÇÕES FINAIS}

DOI: $10.29327 / 214648.9 .33-4$ 
A presente pesquisa teve por objetivo identificar como a integração regional beneficiou a educação no contexto marginalizado de fronteira do Brasil com o Paraguai. O Mercosul, enquanto um bloco econômico, buscou, por meio do SEM, promover ações de integração regional também pela educação. A evolução das políticas educacionais para a fronteira aponta para uma organização e para o estabelecimento de parcerias importantes, com a inserção das universidades, das Secretarias de Educação, tanto estaduais quanto municipais, para a efetivação da política de integração regional entre os países mercosulinos. Ao longo do trabalho buscou-se responder ao seguinte questionamento: $\mathrm{O}$ processo de integração regional trouxe benefícios para a educação na fronteira do Brasil com o Paraguai? E, pode-se afirmar que a integração regional por meio da educação não teve longevidade com a descontinuidade das ações de formação continuada para os professores com a finalização, não formal, do PEIF em todo o Brasil.

As discrepâncias econômicas e de dimensões territoriais das duas nações representam gatilhos para os desafios educacionais presentes no contexto fronteiriço, como a morosidade na execução das ações do Planos do SEM que prejudicaram a qualidade da educação entre os países do bloco, a dificuldade na promoção de aperfeiçoamento para os todos os professores e de ampliação da política educacional. Além das inconsistências na oferta de educação intercultural, como o preconceito entre brasileiros e paraguaios, o embaraço com a linguística ao propor o ensino nas línguas (Língua Portuguesa e Espanhol/Guarani), a própria visão preconceituosa da fronteira e situações relacionadas à segurança das pessoas, representam questões desafiadoras.

Portanto, a integração regional, advinda do processo de globalização instaurado no mundo, atingiu seu objetivo parcialmente entre os países sul-americanos com a constituição do Mercosul e do SEM. Entre o Brasil e o Paraguai conclui-se que houve o início desse processo, mas não sua efetivação, pois a fragilidade demonstrada pelo bloco, até mesmo pela morosidade das ações e a própria saída do Paraguai do Mercosul em 2013, declara que ainda há muito a ser feito pelos governantes de cada país na busca pela integração regional, bem como a diminuição da marginalização da fronteira.

\section{REFERÊNCIAS BIBLIOGRÁFICAS}

ALBUQUERQUE, J. L. Conflito e integração nas fronteiras dos "brasiguaios". Caderno CRH, Salvador, v. 23, n. 60, p. 579-590, set./dez. 2010.

ALVARES, A. de L. T. Educação superior além-fronteiras: um olhar sobre as estratégias institucionais para atratividade de estudantes brasileiros. 2015. $169 \mathrm{f}$. Dissertação (Mestrado em Educação). Faculdade de Educação, Universidade Federal da Grande Dourados, Dourados, 2015. 
ANDRÉS A. A educação superior no setor educacional do Mercosul. Consultora Legislativa da Área XV. Educação, Cultura e Desporto, dez. 2010.

BANCO MUNDIAL, PIB per capita (US \$ corrente). The World Bank, 2016. Disponível em: https://www.worldbank.org/en/home. Acesso em: 01 fev. 2021.

BORGES. P. Programa Escolas Interculturais de Fronteira: uma proposta pedagógica intercultural. In: BRASIL, TV Escola. Salto para o Futuro. Escolas Interculturais de Fronteira. Ano XXIV - Boletim 1, mai. 2014.

BRASIL. Ministério da Educação. Portaria n 798, de 19 de junho de 2012. Institui o Programa Escolas Interculturais de Fronteira, que visa a promover a integração regional por meio da educação intercultural e bilíngue. Brasília, DF: Ministério da Educação [2012] Disponível em: http://educacaointegral.mec.gov.br/images/pdf/port_798_19062012.pdf. Acesso em: 01 mai. 2020.

BRASIL. Ministério da Integração Nacional. Faixa de Fronteira: Programa de Promoção do Desenvolvimento da Faixa de Fronteira (PDFF). Brasília, DF: Ministério da Integração Nacional [2015]. Disponível em: http://www.integracao.gov.br/c/document_library/get_ file?uuid=e5ba704f-5000-43df-bc8e-01df0055e632\&groupId=10157. Acesso em: 12 dez. 2020.

BRASIL. Instituto Brasileiro de Geografia e Estatística. Dados demográficos. Brasília, DF: Instituto Brasileiro de Geografia e Estatística, [2017]. Disponível em: http://www.cidades.ibge.gov.br/temas.php?lang=\&codmun=500660\&idtema=130\&sear ch=mato-grosso-do-sul ponta-poralestimativa-da-populacao-2015-. Acesso em: 18 jul. 2020 .

CELLARD, A. A análise documental. In: POUPART, J.; DESLAURIERS, J.P.; GROULX, L. (org.). A pesquisa qualitativa: enfoques epistemológicos e metodológicos. Petrópolis: Vozes, p. 295-334, 2008.

CHESNAIS, F. A globalização e o curso do capitalismo de fim-de-século. Traduzido do francês por Catherine Marie Mathieu. Economia e Sociedade, Campinas, n. 5, p. 1-30, dez.1995.

CRISTOFOLI, M. S. Políticas de Línguas Estrangeiras na Educação Básica: Brasil e Argentina entre avanços, percalços. 2010. 208 f. Tese (Doutorado em Educação) Faculdade de Educação, Universidade Federal do Rio Grande do Sul, Porto Alegre, 2010.

CUNHA, C. da. O Mercosul e a educação básica. In: Em Aberto, Brasília, n. 68, p. 915. 1995. 
DALE, R. Globalização e educação: demonstrando a existência de uma "cultura educacional mundial comum" ou localizando uma "agenda globalmente estruturada para a educação"? Educação \& Sociedade, Campinas, v. 25, n. 87, p. 423-460, maio/ago. 2004.

FERNANDES, R. M. C. HELLMANN, A. Dicionário crítico: política de assistência social no Brasil. Porto Alegre: Editora da UFRGS/CEGOV, 2016.

FLORES, O. V. O Programa Escola Intercultural Bilíngue de Fronteira: um olhar para novas políticas linguísticas. 2012. 127 f. Dissertação (Mestrado em Linguagem e Sociedade) - Centro de Educação, Comunicação e Artes, Universidade Estadual do Oeste do Paraná, Cascavel, 2012.

GATTI, B. A. Educação, escola e formação de professores: políticas e impasses. Educar em Revista. Curitiba, n. 50, p. 51-67, out./dez. 2013.

GIDDENS, A. As consequências da modernidade. São Paulo: Editora Unesp, 1991.

HAYGERT, S.; STURZA, E. R. Reflexões sobre o Programa de Escolas Interculturais de Fronteira como uma política linguística. Linguagens e Cidadania, Santa Maria, v. 17, p. 1-14, jan./dez. 2015

HELD, D.; MCGREW, A. Prós e contras da globalização. Rio de Janeiro: Jorge Zahar, 2001.

HIRST, P.; THOMPSON G. Globalização em questão: a economia internacional e as possibilidades de governabilidade. Petrópolis, RJ: Vozes, 1998.

IANNI, O. Globalização e crise do Estado-Nação. Revista Estudos de Sociologia, São Paulo, v. 4, n. 6, p. 129-135. 1999. Disponível em: https://periodicos.fclar.unesp.br/estudos/article/ download/753/618. Acesso em: 03 jun. 2020.

JESSOP, B. A globalização e o Estado nacional. Crítica Marxista, São Paulo, v. 1, n. 7, p. 9-45, 1998.

MARIANO, K. P. Globalização, integração e o estado. Lua Nova, São Paulo, n. 71, p.123-168. 2007.

MARIANO, K. L. P.; ROMERO, A. M. S.; RIBEIRO, C. C. N. Percepções governamentais sobre a integração regional na América do Sul. Boletim de Economia e Política Internacional, Brasil, n. 21, p. 33-43, set./dez. 2015. 
MERCOSUL. Ata de reunião MERCOSUR/RME n. ${ }^{\circ}$, de 27 de novembro de 1992. Brasília, Brasil: Reunião de Ministros de Educação, [1992]. Disponível em: https://documentos.mercosur.int/reuniones/2674. Acesso em: 25 set. 2018.

MERCOSUL. Setor Educacional do Mercosul. Decisão n. ${ }^{0}$ 13, de 10 de dezembro de 1998. Plano Trienal e Metas do Setor Educacional. Montevideo, Uruguai: Setor Educacional do Mercosul, [1998]. Disponível em: http://edu.mercosur.int/esES/decisoes-conselho-mercado-comum-cmc/finish/4-decisoes-decisiones/400-decisaomercosur-cmc-dec-n-13-98.html. Acesso em: 25 set. 2020.

MERCOSUL. Setor Educacional do Mercosul. Plano Estratégico 2001-2005. Montevideo, Uruguai: Setor Educacional do Mercosul, [2001]. Disponível em: http://edu.mercosur.int/es-ES/tratados/finish/7-planos-planes/413-plano-2011-2015versao-portugues.html_. Acesso em: 25 set. 2020.

MERCOSUL. Setor Educacional do Mercosul. Plano de Ação 2011-2015. Montevideo, Uruguai: Setor Educacional do Mercosul, [2011]. Disponível em: http://edu.mercosur.int/es-ES/tratados/finish/7-planos-planes/413-plano-2011-2015versao-portugues.html. Acesso em: 25 set. 2020.

MERCOSUL. Setor Educacional do Mercosul. Plano de Ação 2016-2020. Buenos Aires, Argentina: Setor Educacional do Mercosul, [2016]. Disponível em: http://edu.mercosur.int/es-ES/tratados/viewcategory/7-planos-planes.html. Acesso em: 25 set. 2020 .

NETO, W. A. D. (org.). O Brasil e as novas dimensões da integração regional. Rio de Janeiro: Instituto de Pesquisa Econômica Aplicada (Ipea), 2014.

PALUMBO, D. J. A abordagem de política pública para o desenvolvimento político na América. In: Política de capacitação dos profissionais da educação. Belo Horizonte: FAE/IRHJP, p. 35-61. 1989.

PEREIRA, J. H. do V. Educação na fronteira: o caso Ponta Porã (MS) e Pedro Juan Caballero (PY). Papéis, Campo Grande, v. 18, n. 36, p. 93-106. 2014.

QUEIROZ, L. G. Integração Econômica Regional e Políticas de Saúde: União Europeia e MERCOSUL. 2007. 365 f. Tese (Doutorado em Ciências) - Escola Nacional de Saúde Pública Sergio Arouca, Fundação Oswaldo Cruz, Rio de Janeiro, 2007.

REAL, G. C. M. Impactos da expansão da educação superior na mobilidade estudantil: o eixo Brasil - Paraguai. In: $32^{\text {a }}$ Reunião Anual da ANPEd. Caxambu - MG, 2009. Anais [...]. Caxambu: ANPEd, 2009.

REAL, G. C. M. Avaliação da educação superior no Brasil e no Paraguai: implicações para a construção do Mercosul Educacional. Tópicos Educacionais, Recife, v. 19, n. 1, p. 9-27, jan./jun. 2013. 
RODRIGUES, C. Z. A fronteira como espaço de partida: processos discursivos entrelaçados. In: PINTO, A. C. T.; SILVA, M. R. da. De frente para a fronteira: reflexões sobre a educação em área de fronteira. Chapecó, [s.n.], 2014.

SATO, E. A agenda internacional depois da Guerra Fria: novos temas e novas percepções. Revista Brasileira de Política Internacional, Brasília, v. 43, n.1, p. 138-169, 2000.

SANTOS, T.; JUNIOR, C. A. D., Integração Regional e Educação: O caso do Mercosul. Oikos, Rio de Janeiro, v. 16, n. 2, p. 22-36, 2017.

SILVEIRA, Z. S. Setor educacional do MERCOSUL: convergência e integração regional da educação superior brasileira. Avaliação, Campinas/Sorocaba, v. 21, n. 3, p. 901-927, nov. 2016.

SIMOES, R.; MORINI, C. F. A ordem econômica mundial: considerações sobre a formação de blocos econômicos e Mercosul. Revista Impulso, Piracicaba, n. 31, p. 139154. 2002.

SOUZA, A. R. de. A teoria da agenda globalmente estruturada para a educação e sua apropriação pela pesquisa em políticas educacionais. RBPAE, v. 32, n. 2, p. 463-485, maio/ago. 2016.

SOUZA. K. R. Direito à educação nos países membros do Mercosul: um estudo comparado. 2017. 346 f. Tese (Doutorado em Educação Escolar) - Faculdade de Ciências e Letras, Universidade Estadual Paulista “Júlio de Mesquita Filho”, São Paulo, 2017.

STURZA, E. R. Das experiências e dos aprendizados no Programa Escolas Interculturais de Fronteiras. In: BRASIL, TV Escola. Salto para o Futuro. Escolas Interculturais de Fronteira. Ano XXIV - Boletim 1, mai. 2014.

TORCHI, G. da F. C.; SILVA, C. P. da. O retrato da fronteira Sul-Mato-Grossense por meio da expansão do Programa Escola Interculturais de Fronteira. In: PINTO, A. C. T.; SILVA, M. R. da. Programa Escola Interculturais de Fronteira (PEIF): 10 anos. Tubarão: Copiart, 2016.

VIGEVANI, T.; FAVARON, G. de M.; RAMANZINI JÚNIOR, H.; CORREIA, R. A. O papel da integração regional para o Brasil: universalismo, soberania e percepção das elites. Revista Brasileira de Política Internacional, Rio de Janeiro, v. 51, n. 1, p. 5-27. 2008.

VIZENTINI, P. G. F. O Brasil, o Mercosul e a integração da América do Sul. Revista de Estudos e Pesquisas sobre as Américas, v. 1, n. 1, ago./dez. 2007. 
*Docente da Universidade Federal de Mato Grosso do Sul/Campus de Ponta Porã. Pedagoga. Doutora e Mestre em Educação pela UFGD. Lattes: http://lattes.cnpq.br/8603315352890351. Orcid: https://orcid.org/0000-0002-5785-9727. E-mail: mara.marques@ufms.br

**Docente da Faculdade de Educação e do Programa de Administração Pública em Rede (PROFIAP) da UFGD. Pedagoga. Doutora em Educação pela UNESP e Mestre em Educação pela UFGD. Lattes: http://lattes.cnpq.br/7169364895636739. Orcid: https://orcid.org/0000-0002-8663-4615. E-mail: kellciasouza@ufgd.edu.br 